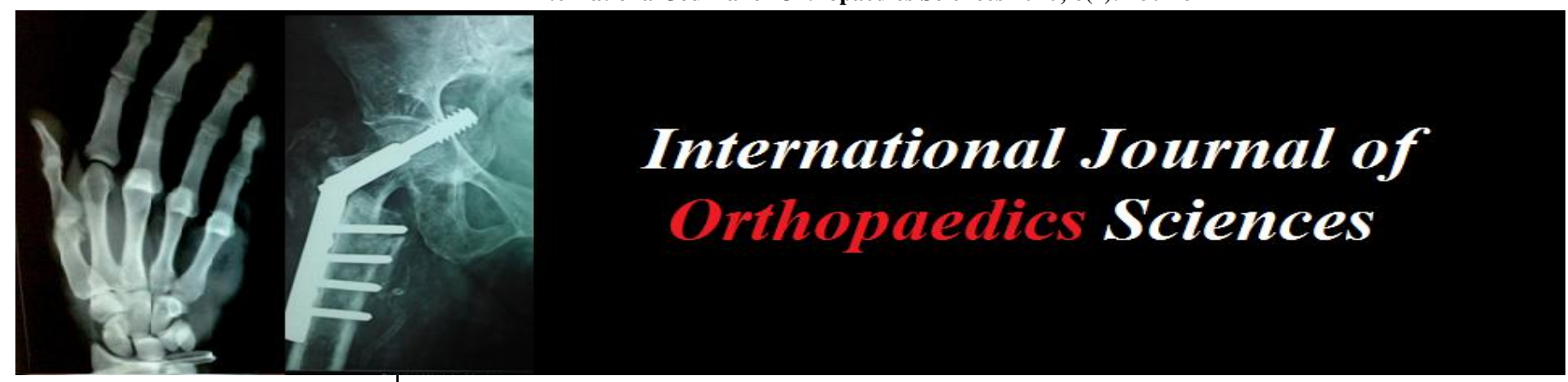

E-ISSN: 2395-1958

P-ISSN: 2706-6630

IJOS 2020; 6(2): 780-784

(C) $2020 \mathrm{IJOS}$

www.orthopaper.com

Received: 01-02-2020

Accepted: 03-03-2020

\section{Dr. Adarsh T}

Assistant professor, Department

of Orthopaedics, JSS Medical

College and Hospital, JSS

Academy of Higher Education

and Research, Mysuru,

Karnataka, India

Dr. Ravishankar Renukarya

Professor, Department of

Orthopaedics, JSS Medical

College and Hospital, JSS

Academy of Higher Education

and Research, Mysuru,

Karnataka, India

\section{Dr. Purushotham Sastry}

Professor and HOD, Department

of Orthopedics, JSS Medical

College \& Hospital, JSS

Academy of Higher Education

and Research, Mysuru,

Karnataka, India

\section{Dr. Mruthyunjaya}

Professor, Department of

Orthopaedics, JSS Medical

College and Hospital, JSS

Academy of Higher Education

and Research, Mysuru,

Karnataka, India

Dr. Mayur C

Junior Resident, Department of Orthopaedics, JSS Medical

College and Hospital, JSS

Academy of Higher Education

and Research, Mysuru,

Karnataka, India

\section{Corresponding Author:}

\section{Dr. Mayur C}

Junior Resident, Department of

Orthopaedics, JSS Medical

College and Hospital, JSS

Academy of Higher Education

and Research, Mysuru,

Karnataka, India

\section{Comparative analysis of Colles' fracture as treated by closed reduction and cast immobilization $\mathrm{v} / \mathrm{s}$ percutaneous $\mathrm{K}$ wire fixation}

\author{
Dr. Adarsh T, Dr. Ravishankar Renukarya, Dr. Purushotham Sastry, \\ Dr. Mruthyunjaya and Dr. Mayur C
}

DOI: https://doi.org/10.22271/ortho.2020.v6.i2m.2136

\section{Abstract}

Background: In Colles' fracture closed reduction and POP cast application has been the mainstay of treatment, difficulty lies in predicting and maintaining the proper reduction due to dorsal communition of fracture. Percutaneous K-wire stabilization is also a widely accepted treatment option for continued maintenance of reduction till fracture union. But there is no consensus on its outcome in comparison to closed reduction and cast application.

Objectives: To evaluate the results of closed reduction and cast application vs closed reduction with percutaneous K-Wire fixation in the treatment of the distal radius extra-articular fractures.

Materials and methods: The study was conducted on 60 patients from September 2017 to April 2019 with extra-articular fractures of distal radius. The cases were randomly divided into two equal groups of 30 patients, group A and B, the first group treated by closed reduction and below elbow cast,while the second group were treated by closed reduction percutaneous K-wire application. The results of both groups were evaluated radiologically and functionally as per our protocol.

Results: At 6 months postoperatively, according to Gartland and Werley, Group A we had 13(43\%) excellent results, $9(30 \%)$ good results, $7(23 \%)$ fair results and $1(3 \%)$ poor results. In group B, 11(36\%) excellent results, $13(43 \%)$ good results, $5(16 \%)$ fair results and $1(3 \%)$ poor results. Our study demonstrates that there is no significant difference in the functional outcome obtained with closed reduction and cast versus closed reduction, K-wire fixation and cast. However, K-wire fixation plays a role in maintaining post-operative reduction and to achieve near normal anatomical union.

Conclusion: Colles' fracture treated by percutaneous K-wire fixation along with below elbow cast provided additional stability and good radiological outcome in comparison to patients treated with closed reduction and below elbow cast alone. However, closed reduction and cast application alone gives same functional outcome as K-wire fixation.

Keywords: Extra articular, Colles' fracture, K-wire fixation, below elbow casting

\section{Introduction}

Abraham Colles of Dublin, Ireland back in 1814 was the one who first described what is now commonly known as Colles' fracture, he had described it as being unique unlike other fractures lacking the typical characteristic of crepitus and abnormal mobility. Distal radius fracture in early days was most common in elderly population and in post menopausal ladies however of late the incidence has increased in younger population because of the high velocity injuries and road traffic accidents ${ }^{[1,2]}$

In the late part of eighteenth century and early nineteenth century disability caused by malunited distal radius fracture was considered acceptable. Patients would get acclimatised to the residual deformity, limitation of range of movement, decreased grip strength. However with changing trends of management and better availability of newer treatment modalities and unacceptability of deformity by the patients a near normal function of wrist had to be achieved [3].

Fractures involving the distal radius which is extra articular can be treated by various modalities like Internal fixation with plate and screws after open reduction, ligamentotaxis following closed reduction of fracture, percutaneous $\mathrm{K}$-wire fixation, closed reduction and 
plaster cast application. However latter two are most frequently done by orthopaedic surgeons for Colles' fracture [3-5].

We have take into consideration lot of things before deciding on the treatment modality. In those patients with low functional demand, advanced age, injury of non-dominant hand, extra-articular fracture along metaphyseal region, fracture can be immobilized in plaster of Paris cast after closed reduction ${ }^{[6,7] \text {. }}$

Pin and plaster technique wherein, the K-wire provides additional stability after closed reduction of fracture while treating this fracture involving distal radius fracture. ${ }^{(8,9)}$ However due to poor bone quality of bone and due to high chance of fracture losing the reduction once edema subsides in elderly patients ,percutaneous K-wire pinning gives the additional support which is needed to maintain the fracture in desired alignment and position ${ }^{[7,10]}$.

Apart from the fracture, the dorsal communition, beyond mid axial plane of radius, the pattern of fracture, intra-articular extension of fracture, association with ulnar fracture, the amount of primary displacement of fracture which includes dorsal tilt more than 20 degrees, radial shortening more than 5 $\mathrm{mm}$, which are the main risk factors for causing instability and these complicated fractures will need more aggressive treatment [11-13]. The variable results obtained by closed reduction methods prompted us to evaluate and to compare the results of extra articular distal radius fractures

The purpose of study undertaken is to determine which among these two methods for management of extra-articular distal radius fracture is statistically better with respect to functional and radiological outcome as assessed by Gartland and Werley demerit scoring system

\section{Objectives}

- Primary objective: Functional evaluation of Colles' Fracture as treated by cast immobilization vs Percutaneous K-wire fixation by Gartland and Werley demerit scoring system with Sarmeinto et al. modification

- Secondary objective: To assess anatomical and radiological congruity of treated cases of Extra-articular distal radius fracture

\section{Materials and methods}

The prospective randomized control study was conducted on 60 patients attending as out-patient or in-patient at Department of Orthopaedics at JSS Medical College and Hospital, Mysuru from September 2017 to April 2019 who have been found to have extra-articular fractures of distal radius and fulfil all the inclusion and exclusion criteria.

All patients with radiologically confirmed extra-articular fractures of distal radius (Colles'), patients who are medically fit, willing for the procedure and consented to be part of the study, patients above the age of 18 years and patients presenting with injuries not older than 2 weeks were included in the study. Patients with intra-articular fractures involving radio-carpal joint, patients with open fractures of distal radius and with neurovascular deficit, fractures in children, patients with previous fractures of the wrist and patients with pathological fractures were excluded from the study.

After getting IEC clearance and informed written consent from patients, history regarding the mode of injury and severity of trauma were noted. Sampling was done by simple randomization of the cases done according to a computerized randomization protocol. All patients were examined thoroughly for general condition, vitals and associated systemic diseases. All routine hematological and radiological investigations were carried out. In our study, patients were allocated randomly into two equal groups, one treated by closed reduction and cast application and the second treated by closed reduction percutaneous K-wire fixation and cast application under brachial or local hematoma block.

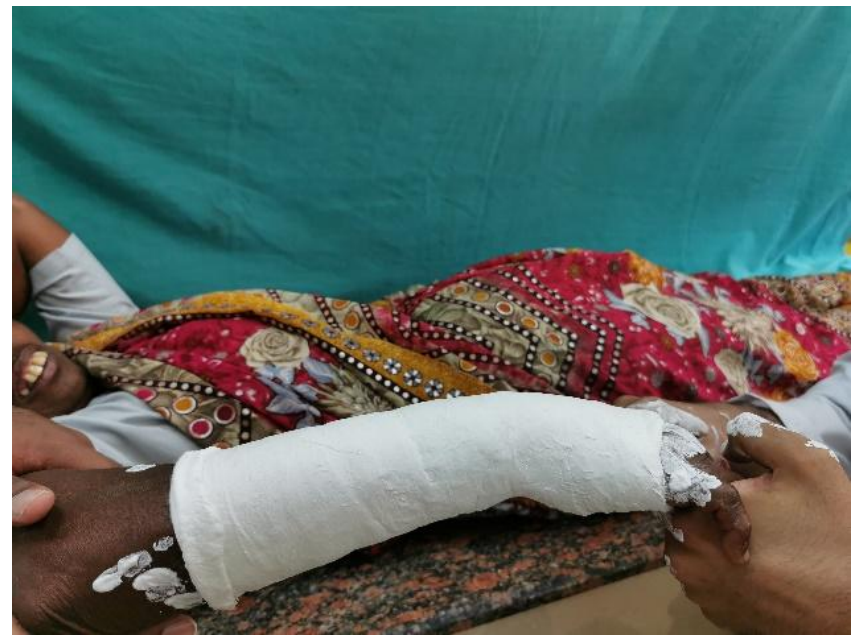

Fig 1: Closed reduction with $\mathrm{B} / \mathrm{E}$ cast in palmar flexion and ulnar deviation

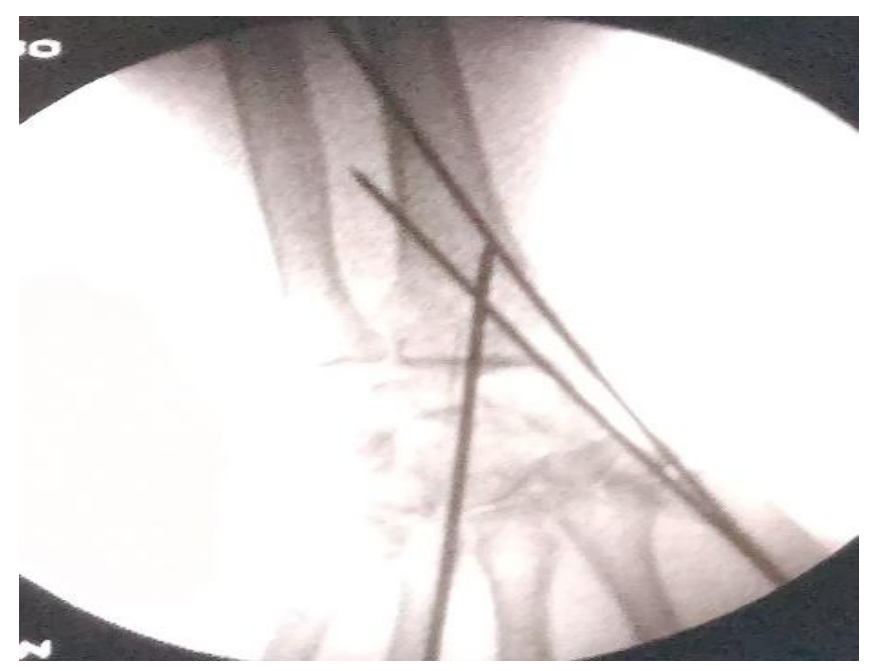

Fig 2: Closed reduction with percutaneous $\mathrm{K}$ wire fixation

Immediate post operative check x-rays were taken in both PA and Lateral, the reduction of fracture was confirmed and any displacements were noted. Patients were discharged after three days with routine POP instructions with active finger, elbow and shoulder exercises. All cases were followed up at the end of $2^{\text {nd }}, 4^{\text {th }}$ and $6^{\text {th }}$ weeks. After 6 weeks K-wires and cast were removed and patient was assessed clinically for fracture union, range of movements and radiological parameters, physiotherapy was advised. After 6 weeks, regular follow up was done at an interval of three months and six months respectively.

The data obtained from the two groups shall be analyzed by using unpaired student's t- test for continuous variables. The results will be analyzed by SPSS version 24.0

\section{Results}

Out of the 60 patients included in the study, 30 patients were divided randomly into 2 different groups. In Group 1, patients were treated with closed reduction and below elbow POP cast 
alone and in group 2, patients were treated with closed reduction of the fracture, percutaneous K-wire fixation and below elbow POP cast.

The mean age of the patients in the two groups combined was 51.27 years. The maximum cases were seen between 51 to 60 years of age in both the groups. The total number of males in the POP cast application and in the percutaneous pinning with cast application were 10 and 19 respectively and the number of female patients in both groups were 12 and 11 respectively. Chi square test among sex difference was 5.406 with p value of 0.02 (statistically significant). The distribution of fractures were classified based on Frykmann classification of distal radius fractures which was shown in table 1.

Table 1: Fracture classification distribution

\begin{tabular}{|c|c|c|c|c|}
\hline \multirow{2}{*}{$\begin{array}{c}\text { Fracture } \\
\text { type }\end{array}$} & \multicolumn{2}{|c|}{ Casting Group } & \multicolumn{2}{c|}{$\begin{array}{c}\text { K-wiring and Casting } \\
\text { Group }\end{array}$} \\
\cline { 2 - 5 } & Frequency & $\%$ & Frequency & $\%$ \\
\hline I & 7 & $23.3 \%$ & 8 & $26.7 \%$ \\
\hline II & 23 & $76.7 \%$ & 22 & $73.3 \%$ \\
\hline \multicolumn{4}{|c|}{ Chi square $=0.89 \mathrm{p}=0.766$} \\
\hline
\end{tabular}

Out of 60 cases, self fall was the most common cause of the fractures with 23 cases in the casting group and 19 cases in the k-wiring and cast group. Road traffic accident was the next most common cause with 6 cases in the cast group and 10 cases in the $\mathrm{k}$ wiring and cast group. There was 1 case of assault leading to fracture in POP cast group. The side distribution in both groups were 14 and 18 right sided fractures in the cast and $\mathrm{k}$ wiring groups respectively \& 16 and 12 left sided fractures in the two groups respectively.

The complications were encountered in both groups, residual pain was the most common with 4 patients in the casting and 5 in the k-wiring group. Stiffness of wrist was the next common complication with 6 and 7 cases in both groups respectively. One patient in each group had reduced hand grip and one patient in casting group had sudeck's osteodystrophy and one patient in k-wiring group had reduced grip. The parameters analysed with radiological outcome were shown in table 2.

Table 2: Radiological outcome

\begin{tabular}{|c|c|c|c|c|c|}
\hline \multirow{2}{*}{$\begin{array}{c}\text { Radiological } \\
\text { parameters }\end{array}$} & \multicolumn{2}{|c|}{ Casting Group } & \multicolumn{2}{|c|}{$\begin{array}{c}\text { K-wiring and } \\
\text { Casting Group }\end{array}$} & \multirow{2}{*}{$\begin{array}{c}\text { P } \\
\text { value }\end{array}$} \\
\cline { 2 - 5 } & Mean & $\begin{array}{c}\text { Standard } \\
\text { Deviation }\end{array}$ & Mean & $\begin{array}{c}\text { Standard } \\
\text { Deviation }\end{array}$ & \\
\hline $\begin{array}{c}\text { Radial height } \\
\text { (mm) }\end{array}$ & 5.06 & 1.17 & 8.9 & 1.47 & 0.0001 \\
\hline $\begin{array}{c}\text { Radial inclination } \\
\text { (degrees) }\end{array}$ & 9.16 & 1.48 & 14.13 & 1.48 & 0.0001 \\
\hline $\begin{array}{c}\text { Volar tilt } \\
\text { (degrees) }\end{array}$ & 2.86 & 0.93 & 5.5 & 0.73 & 0.0001 \\
\hline
\end{tabular}
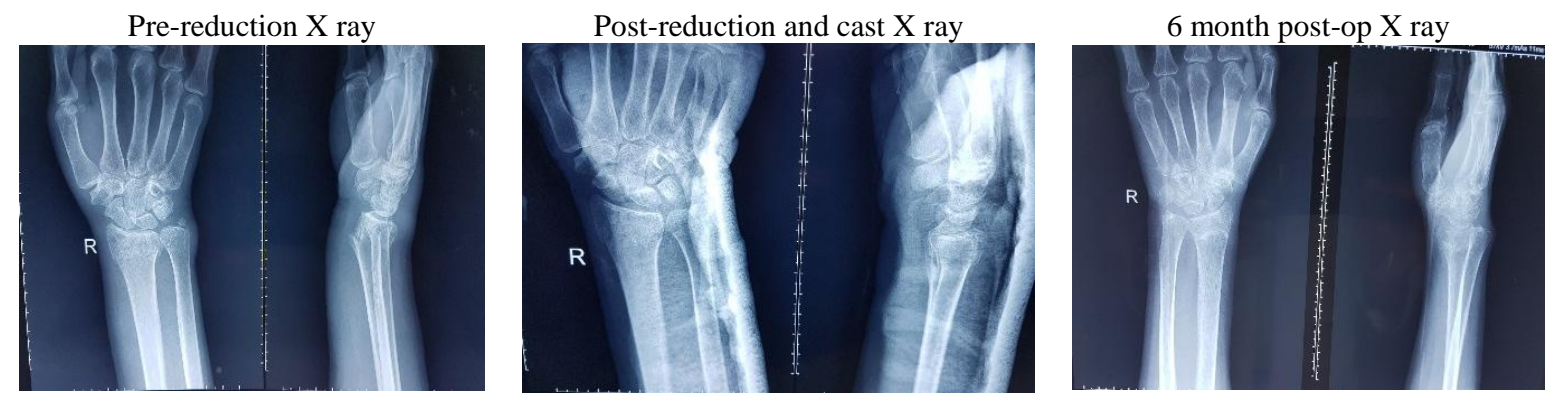

Fig 3: Radiographs of colle's fractures treated with closed reduction and B/E POP casting
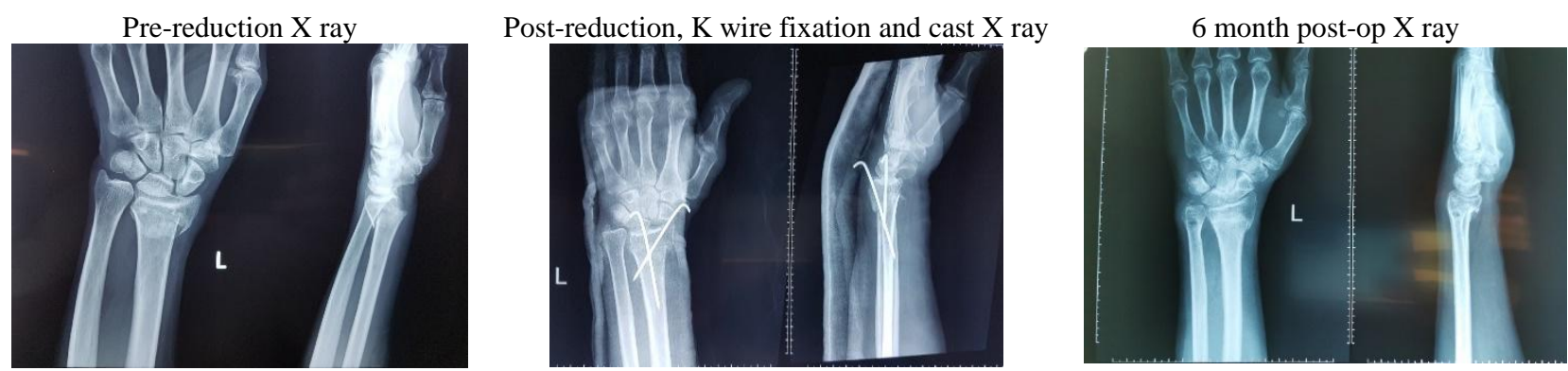

Fig 4: Radiographs of colle's fractures treated with closed reduction and percutaneous $\mathrm{K}$ wire fixation

Functional outcome grading were done according to Gartland and Werley demerit scoring system with Sarmiento modification (as shown in graph 1). In group treated by closed reduction and POP cast alone had 13 excellent, 9 good, 7 fair and 1 poor outcome while in group treated by closed reduction, percutaneous K-wire fixation and POP cast had 11 excellent, 13 good, 5 fair and 1 poor outcome. ' $\mathrm{P}$ ' value obtained as assessed by unpaired students t-test was 0.746 which is statistically insignificant with respect to functional outcome amongst the two groups. 


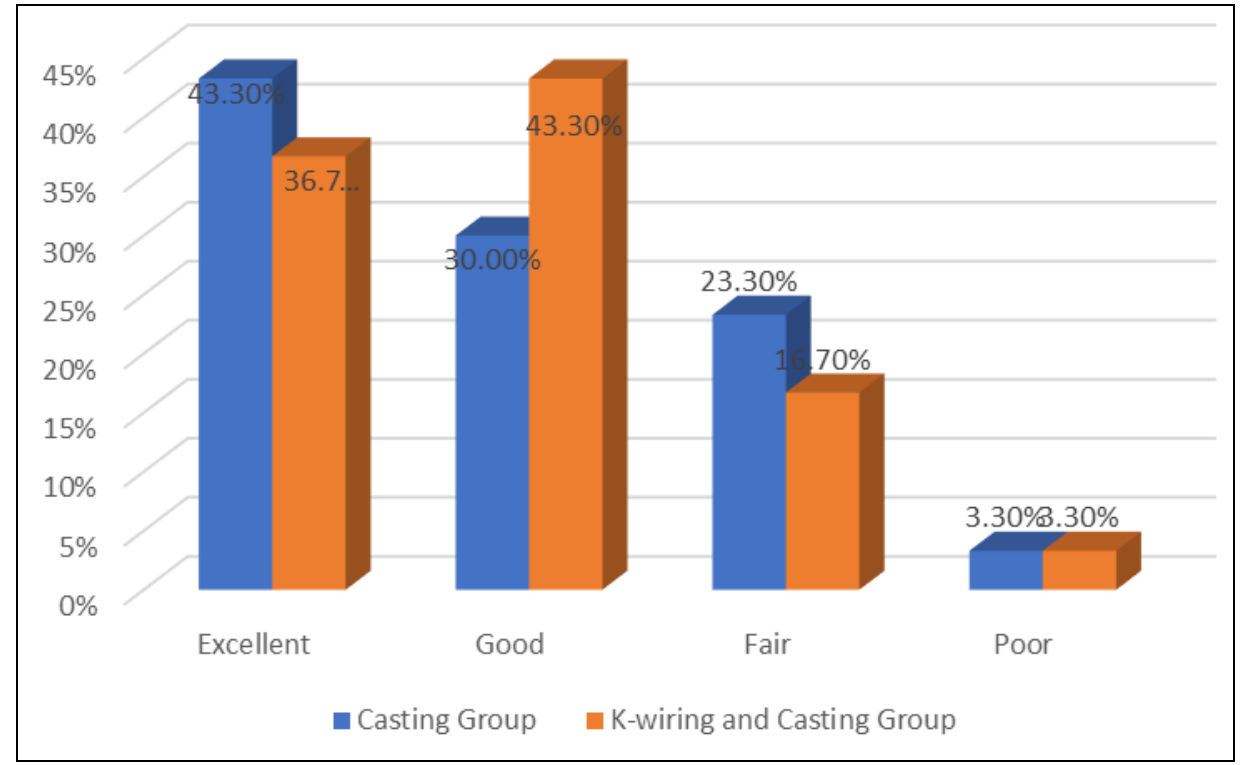

Graph 1: Functional outcome with Gartland and Werley demerit scoring system with Sarmiento modification

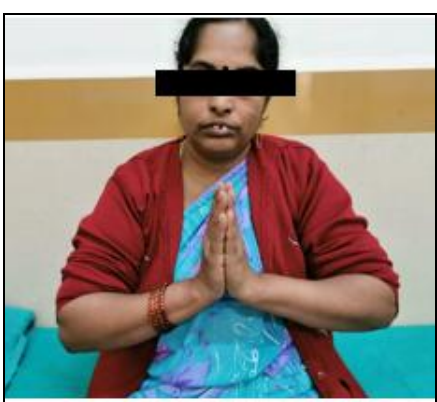

Dorsi flexion

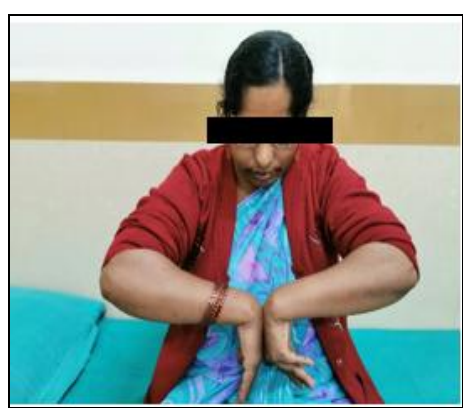

Palmar flexion

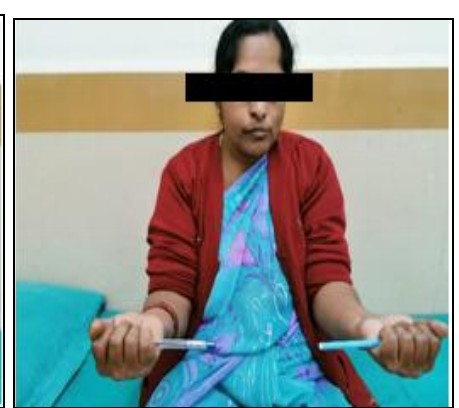

Supination

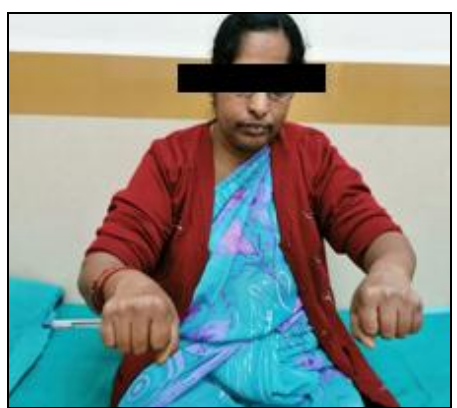

Pronation

Fig 5: Functional range of movements with closed reduction and B/E POP casting

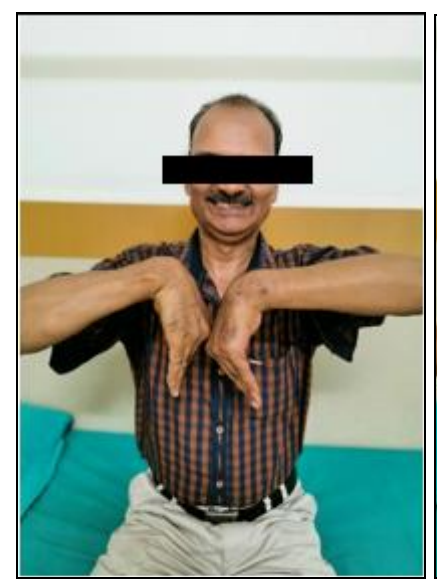

Palmar flexion

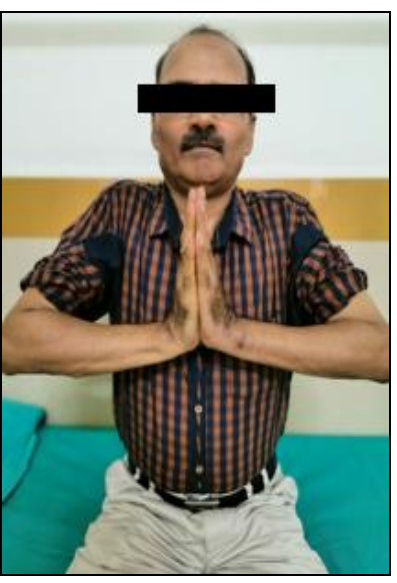

Dorsi flexion

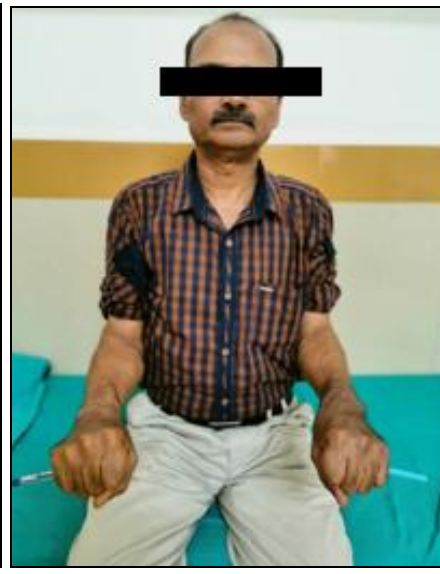

Pronation

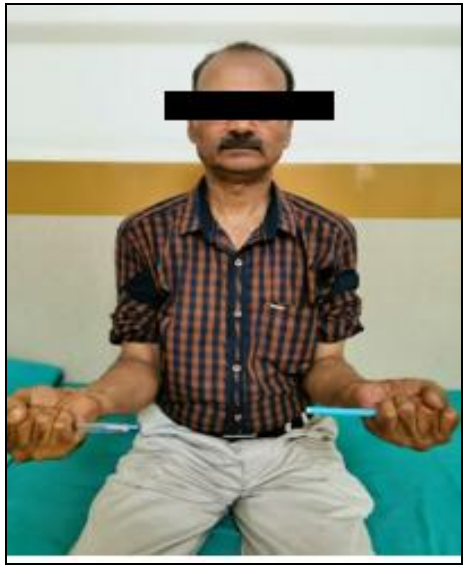

Supination

Fig 6: Functional range of movements with closed reduction and percutaneous $\mathrm{K}$ wire fixation

\section{Discussion}

Fracture of distal end of radius is most common upper extremity fracture accounting for $17.5 \%$ of all fractures in adults. Previously the incidence of the fracture was more common in elderly population due to poor bone quality however due to high velocity injuries and road traffic accidents the mean age group of the patients has reduced ${ }^{[4]}$. In study by Young et al. ${ }^{[10]}$, he noted that due to increase in the life expectancy in general, orthopedics residents have to deal with these fractures focusing on treatment of these osteoporotic fractures especially in woman post menopause. There have been various studies like the ones by Jupiter et al.
[3], Ericson et al. ${ }^{[14]}$, Porter et al. ${ }^{[15]}$, Cooney et al. ${ }^{[5]}$ which have suggested anatomical result and functional outcome are directly related, but most number of patients end up doing well even though they have obvious deformity.

In most of the cases anatomical congruity can be attained by closed reduction of the fracture however problem lies in maintaining the reduction till the fracture union. Clancy ${ }^{[16]}$, Atkinson [17], Shankar ${ }^{[18]}$ and Waltan ${ }^{[11]}$ conducted various studies on heterogeneous group of people belonging to different age groups and different modalities of treatment.

Jupiter et al. ${ }^{[3]}$ in their study had given overview about the extra articular distal radius fracture treated by K-wire fixation. 
Clancey et al, Atkinson et al. and Rodrigues et al. further in their studies on distal radius fracture compared between the treatment modalities for extra articular fractures ${ }^{[16,17,19]}$ All of them claimed good results however with the lack of controlled trials no clear consensus could be drawn.

Kurup et al. ${ }^{[20]}$ studies regarding late collapse of the fracture after removal of the K-wire after 6 weeks, result showed that there was late collapse after K-wire was removed after 6 weeks. Stoffelen et al. [21] conducted a prospective randomized trial of closed reduction versus intrafocal pinning for extra articular fracture claiming no difference in outcome between the two groups.

In the study conducted by us, we compared two different treatment modalities for extra articular distal radius fractures. In both the groups, fractures was immobilized in below elbow POP cast for 6 weeks. Jupiter et al. ${ }^{[3]}$ and Sahin et al. ${ }^{[22]}$ have found that there is no significant difference in the outcome of fracture while treating the fractures by above or below elbow POP cast

In our study we found that radiological parameters were better in group treated by closed reduction and percutaneous $\mathrm{K}$-wire fixation group. Our study result was comparable to studies done by Azzopardi et al., ${ }^{[6]}$ Abhishek et al., ${ }^{[23]}$ and R R Bagul et al. ${ }^{[24]}$. The $\mathrm{p}$ value obtained by unpaired student's $\mathrm{t}$ test in all radiological parameters was found to be 0.0001 which is considered statistically significant.

Functional outcome analysis was done by Gartland and Werley Demerit scoring system. Azzopardi et al. ${ }^{[6]}$ and Wong et al. ${ }^{[7]}$ used Mayo wrist scoring system and activities of daily living respectively. In our study we found that the functional outcome as per demerit score system of Gartland and Werley obtained amongst the two groups was not statistically significant with the student's unpaired t test yielding a $\mathrm{p}$ value of 0.746 .

Limitations in the study were relatively small sample size, interobserver variability \& error in subjective evaluation by Gartland and Werley demerit scoring system, insufficient data to analyse the intra-articular extension of fracture and variability in the type of anaesthesia used for fixation of fracture in different groups might alter fracture reduction.

\section{Conclusion}

We conclude that extra-articular distal radius fractures (Colles') as treated by percutaneous K-wire fixation along with below elbow cast provided additional stability and good radiological outcome in comparison to patients treated with closed reduction and below elbow cast alone.

\section{References}

1. Porter M, Stockley I. Fractures of distal radius: intermediate and end results in relation to radiographic parameters. Clin Orthop. 1987; 220:241-52.

2. Cooney WP, Dobyns JH, Linscheid RL. Complications of Colles fractures fractures. J Bone Joint Surg (Am). 1980; 62-A:613-19.

3. Jupiter JB. Fractures of distal end of radius. J Bone Joint Surg (Am). 1991; 73-A:461-9.

4. Ring D, Jupiter JB. Percutaneous and limited open fixation of fractures of distal end of radius. Clinical Orthop. 2000; 375:105-15.

5. Cooney WP, Lindscheid R, Dobyns J. External pin fixation for unstable Colles fracture. J Bone Joint Surg (Br). 1979; 61-B:840-5.

6. Azzopardi T, Coultan T. A prospective randomized study of immobilization in cast versus supplementary percutaneous pinning. J Bone Joint Surg. 2005; 87:837.

7. Wong TC, Chiu CY. Casting versus percutaneous pinning for extra-articular fractures of distal radius in an elderly Chinese population. J Hand Surg Eur. 2010; 35(3);202-8.

8. Rayhack JM. The history and evolution of percutaneous pinning of distal radius fractures. Orthop Clin North Am. 1993; 24:287-300.

9. Simic PM, Weiland AJ. Fractures of the distal radius: changes in treatment over past two decades. J Bone Joint Surg (Am). 2003; 85:552-64.

10. Young BT, Ryan GM. Outcome following non operative treatment of displaced distal radius fractures in low demand patients older than 60 years. J Hand Surg (Am). 2000; 25:19-28.

11. Walton NP, Brammar TJ. Treatment of unstable distal radius fractures by intrafocal, intramedullary $\mathrm{K}$-wires. Injury. 2001; 32:383-9.

12. Kurup HV, Madalia V. Variables affecting stability of distal radius fractures fixed with $\mathrm{K}$-wires ; a radiological study. Eur J Orthop Surg Traumatol. 2005; 15:135-139.

13. Egol KA, Walsh M. Distal radius fractures in operative versus non operative treatment. J Bone Joint Surg. 2010; 92:1851-7.

14. Van Der Linden W, Ericson R. Colles fracture: how should its displacement be measured and how should it be immobilized. J Bone Joint Surg. 1981; 63:1285-8.

15. Porter M, Stockley I. Fractures of distal radius: intermediate and end results in relation to radiographic parameters. Clin Orthop. 1987; 220:241-52.

16. Clancey G. Percutaneous K-Wire fixation of colles fractures, a prospective study of thirty cases. J Bone Joint Surg (Am). 1984; 66-A:1008-14.

17. Mah ET, Atkinson RN. Percutaneous K-Wire stabilization following closed reduction of colles fractures. J hand Surg (Am). 1992; 17:55-62.

18. Shankar NS, Craxford AD. Comminuted colles fracture: a prospective trial of management. J R Coll Surg Edin. 1992; 37:199-202.

19. Rodriguez Merchen EC. Plaster cast versus percutaneous pin fixation for comminuted fractures of distal end radius in patients between 46 to 65 years of age. J Ortho Trauma. 1997; 11:212-17.

20. Kurup HV, Mandalia VM, Shaju KA, Singh B, Beaumont AR. Late collapse of distal radius fractures after K-wire removal: is it significant? J Orthop Traumatol. 2008; 9:69-72.

21. Stoffelen DV, BroosPL. Closed reduction versus Kapandji-pinning for Extraarticular distal radius fractures. J Hand Surg (Br). 1999; 24:89-91.

22. Shain M, Tasbas BA. The effect of long and short term casting on stability of reduction and bone mineral density in conservative treatment of colles fracture. Acta orthop Traumatol Truc. 2005; 38:30-4.

23. Das AK, Sundaram N. Percutaneous pinning for non comminuted extra articular fractures of distal radius. Indian J Orthop. 2011; 45:422-6.

24. Sandhu HS, Singh M. Closed reduction and percutaneous K-wire fixation in Colles fracture Indian J Orthop. 1986; 20:197-203. 